\title{
Editorial
}

\section{Atmospheric Pressure Plasma Polymerization}

\author{
Rino Morent $^{*}$,
}

Research Unit Plasma Technology, Department of Applied Physics, Faculty of Engineering and Architecture, Ghent University, Sint-Pietersnieuwstraat 41, B-9000 Ghent, Belgium

Plasma polymerization offers unique opportunities for modifying material surfaces by deposition of a thin polymer film. The unique characteristics of such plasma polymerised films result in great interest for those films in research and industry. The plasma-deposited films are free of pinholes and highly cross-linked. This makes them insoluble, chemically inert, thermally stable and mechanically though. Moreover, such films are often highly coherent and adherent to a variety of substrates including conventional polymer, glass and metal surfaces. These excellent properties make plasma polymerized films suitable for many practical applications in the field of mechanics, electronics and optics.

Low pressure plasma polymerization is already a wellestablished and often studied technology. However, this

*Address correspondence to this author at the Research Unit Plasma Technology, Department of Applied Physics, Faculty of Engineering and Architecture, Ghent University, Sint-Pietersnieuwstraat 41, B-9000 Ghent, Belgium; Tel: +32-(0)9-264.42.57; Fax: +32-(0)9-264.41.98;

E-mail: Rino.Morent@UGent.be

${ }^{\S}$ Guest Editor technology needs expensive vacuum systems which is the largest shortcoming of this low pressure technology in industrial applications besides the limitation to batch processes. Therefore, to sidestep these limitations, substantial efforts are made in evolving alternative techniques. One of the most promising approaches to deposit polymer films in a more flexible, reliable, less expensive and continuous way of treatment are atmospheric pressure plasmas. Since the late nineties, a lot of research has been done on the development of plasma polymerization at elevated pressure.

This special issue presents three different papers related to atmospheric pressure plasma polymerization. The first two papers describe plasma polymerization at atmospheric pressure of poly(ethylene glycol-co-styrene) films and polypyrrole. Pre-treatment with plasma of the substrate before plasma deposition is a frequently applied technique and the time between treatment and effective polymerization is an important factor due to the ageing behaviour of the treated sample. In this view, the third paper investigates the control of this ageing behaviour of a substrate after atmospheric pressure plasma treatment.

(C) Rino Morent; Licensee Bentham Open.

This is an open access article licensed under the terms of the Creative Commons Attribution Non-Commercial License (http://creativecommons.org/licenses/by-nc/3.0/) which permits unrestricted, non-commercial use, distribution and reproduction in any medium, provided the work is properly cited. 